\title{
ON WETTING OF DENSE ALUMINA SUBSTRATE BY LOW ALLOY STEEL CONTAINING OXYGEN
}

\author{
Vlastimil NOVÁK, Lenka ŘEHÁČKOVÁ, Silvie ROSYPALOVÁ, Dalibor MATÝSEK, \\ Bedřich SMETANA, Markéta TKADLEČKOVÁ, Michal SNIEGOŇ, Petra VÁŇOVÁ, \\ Kateřina KONEČNÁ, L'ubomíra DROZDOVÁ
}

VSB -Technical University of Ostrava, Ostrava, Czech Republic, EU, vlastimil.novak@vsb.cz

https://doi.org/10.37904/metal.2021.4078

\begin{abstract}
This investigation was carried out to determine the wetting characteristics of low alloy steel grades that contained, among other elements, chromium around $5 \mathrm{wt} . \%$ and oxygen up to approximately $400 \mathrm{ppm}$. The tests were performed from the melting temperature to a temperature of $1,600{ }^{\circ} \mathrm{C}$ using a high-temperature observation furnace CLASIC operating under non-oxidizing conditions. The influence of oxygen on the examined steel's wetting behavior, i.e., the temperature dependence of surface tension and wetting angle, was found and verified by statistical analysis using the Kruskal-Wallis test. In addition, the phase transition temperatures, ascertained from DTA measurements, were in strong correlation with those theoretically calculated. To provide better insight into the wetting mechanism, SEM/EDX analyses of the wetted alumina surface and of the vertical cross-section of the steel/alumina interface were made using a scanning electron microscope (SEM) JEOL 6490 LV. Beyond the mentioned techniques, the study was accompanied by calculations performed in FactSage oxide database.
\end{abstract}

Keywords: Wetting, phase interface, chromium, oxygen, steel

\section{INTRODUCTION}

The low-alloy steels belong to a group of ferrous materials containing alloying elements in an amount less than that of stainless steels $(<10 \%)$ and greater than $2.07 \%$ [1]. It is a wide variety of steel grades with specific challenges concerning fabrication, welding, and application. This requires, among others, detailed knowledge of their metallurgical structure, thermodynamic, rheological, and surface properties. Their mechanical characteristics and resistance to rust are better compared to plain carbon steels. Those based on chromium and molybdenum series are important due to their creep-resistant level, high-temperature proof strength, and impact/toughness resistance [2,3]. The addition of chromium and nickel improves thermal stability and impairs corrosion resistance, making these steels popular for applications exposed to elevated temperatures without getting too hot [4]. Besides, low alloy steels are used mainly in the nuclear industry for cooling and piping systems, containers, structural materials, and rebars in concrete [5].

As outlined above, surface properties (surface tension in particular) are among the industry's key characteristics. Surface tension is a physical force arising from the fact that bulk atoms interact with surrounding atoms gaining zero net force, contrary to the surface atoms subjected to a net inward force from the neighbor atoms. Regarding a multicomponent alloy, atoms whose energy state is affected negligibly by the surface are preferably segregated in the surface. Oxygen is strongly surface-active, and its energy changes concerning segregation are relatively large compared to most metals. In other words, it influences the surface tension on a grander scale [6,7]. For molten iron, the oxygen partial pressure around $0.01 \mathrm{~Pa}$ decreased the surface tension by several percent, changed the surface tension temperature coefficient from positive to negative, and altered the course of surface tension temperature dependence to a boomerang - like shape [8]. 
Similar results were achieved by Morohoshi et al. when the oxygen activity was controlled between $10^{-12}$ and $10^{-10}$ and carbon activity was kept at $10^{-3}$ [9]. Looking at more complicated systems, oxygen acts as a surfaceactive element, mainly reducing surface tension, thus respecting the isothermal dependence of surface tension on oxygen activity [10]. It is also worth underlining that, for polycomponent steels, the surface properties are hard to model, and therefore these properties can be obtained primarily by experiment [11].

In this study, we have assessed the effect of oxygen and temperature on the surface tension of low-alloyed steels varying in oxygen content. Furthermore, we also focused on the interactions between steel and corundum substrate and, in particular, on the wetting mechanism.

\section{EXPERIMENTAL RESEARCH}

\subsection{Preparation of alloy samples}

Three alloy samples, the composition of which is listed in Table 1, were measured by the sessile drop method to determine the surface properties. The samples were cylindrical ( $5 \mathrm{~mm}$ diameter $\times 5 \mathrm{~mm}$ height) and, before the experiment, they were mechanically cleaned and washed in acetone. The corundum substrates (dense alumina, $98 \mathrm{wt} . \% \mathrm{Al}_{2} \mathrm{O}_{3}$ ) were pretreated by heating at $1,150^{\circ} \mathrm{C}$ for 6 hours, and shortly before the wetting test, they were cleaned with acetone.

Table 1 Composition of steel samples

\begin{tabular}{|c|c|c|c|c|c|c|c|c|}
\hline \multirow{2}{*}{ Sample } & $\mathbf{O}$ & $\mathbf{C r}$ & Co & S & P & C & Ni & N \\
\cline { 2 - 9 } & $(\mathrm{ppm})$ & \multicolumn{7}{|c|}{$($ wt. \%) } \\
\hline $\mathbf{1}$ & 236 & 4.645 & 0.023 & 0.006 & 0.004 & 0.003 & 0.002 & 0.002 \\
\hline $\mathbf{2}$ & 317 & 4.553 & 0.027 & 0.006 & 0.005 & 0.002 & 0.003 & 0.003 \\
\hline $\mathbf{3}$ & 367 & 4.386 & 0.009 & 0.007 & 0.003 & 0.003 & 0.002 & 0.002 \\
\hline
\end{tabular}

The content of other elements $\mathrm{Si}, \mathrm{Al}, \mathrm{Cu}, \mathrm{Ti}, \mathrm{Mo}, \mathrm{V}$ and $\mathrm{B}$ was less than $10 \mathrm{ppm}$, approximately $95 \%$ remainder corresponds to iron.

\subsection{Wetting tests}

The tests were performed in the observation furnace Clasic starting from laboratory temperature to $1,600^{\circ} \mathrm{C}$ with a heating rate of $5^{\circ} \mathrm{C} \cdot \mathrm{min}^{-1}$. After sealing, the furnace was evacuated to approximately $0.1 \mathrm{~Pa}$ and washed with argon (>99.9999\%). An inert atmosphere of argon was maintained during the measurement to prevent oxidation of the sample. A camera CANON EOS 550D took the images of sitting melted droplets. For further details, see article [12].

\subsection{Experimental methods}

The semiquantitative $X$-ray microanalysis was performed using a scanning electron microscope JEOL 6490LV, equipped with EDX analyzer INCA in the mode of backscattered electrons. The experiments were performed with settings: thermo-emission cathode $\mathrm{LaB}_{6}$, voltage $20 \mathrm{kV}$, resolution of $3.0 \mathrm{~nm}$, low vacuum. XRD (X-ray powder diffraction) was carried out by a Bruker-AXS D8 Advance diffractometer with CuKa filtered radiation, voltage $40 \mathrm{kV}$, current $40 \mathrm{~mA}$, step by step mode of $0.014^{\circ} 2 \Theta$, total time on step $25 \mathrm{~s}$, and angular extent 5$80^{\circ} 2 \Theta$. This device operates with Bruker AXS Diffrac, Bruker EVA, and Bruker Topas software. DTA (Differential Thermal Analysis) experimental measurements were made by Setaram Setsys 18TM instrument equipped with S-type thermocouples and at a heating rate of $10^{\circ} \mathrm{C} \mathrm{min}^{-1}$ under an inert atmosphere of argon. Liquidus temperatures were corrected considering the heating rate and sample mass. Interaction between steel and corundum substrate and phase growth depending on temperature were calculated using FactSage 7.2 with databases FToxid, FSsteel and FactPS. 


\section{RESULTS AND DISCUSSION}

\subsection{Wetting tests}

Figure 1 depicts the temperature dependence of steel surface tension. Samples showed a moderate increase in surface tension with temperature. In other words, the temperature coefficient of surface tension was positive (Table 2). This is related to the sulfur contents that are equal to or greater than $60 \mathrm{ppm}$. Furthermore, it is evident that oxygen affected the surface tension, i.e., with increasing oxygen content, the surface tension decreased.

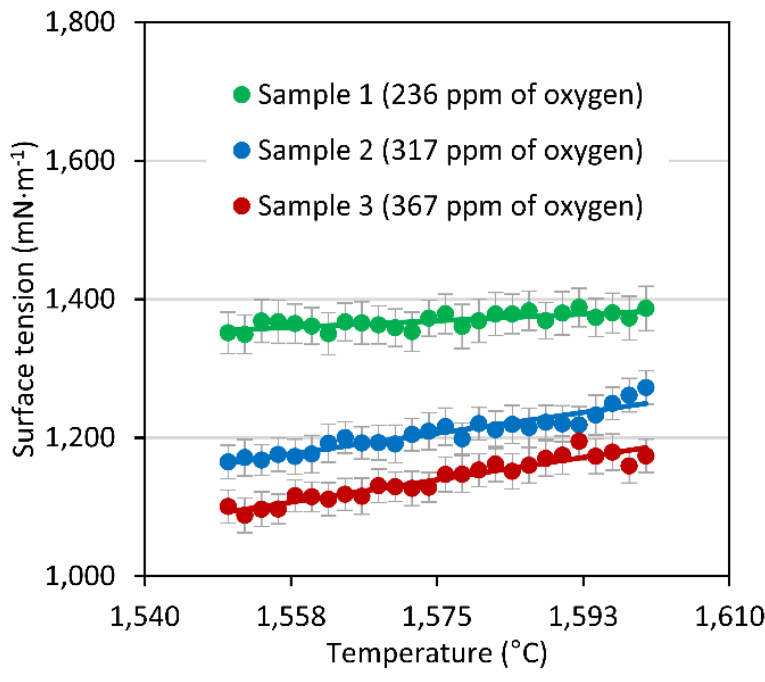

Figure 1 Surface tension as a function of temperature

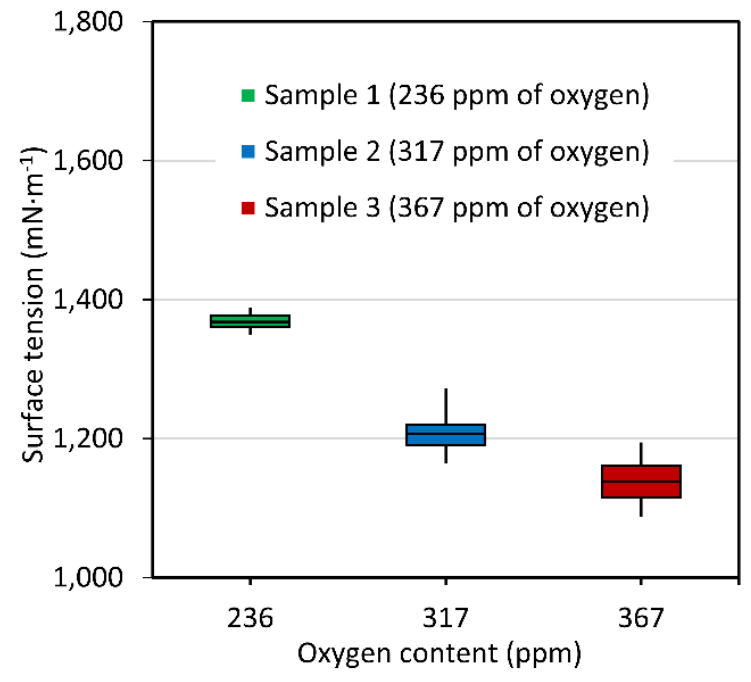

Figure 2 Boxplot of oxygen effect on surface tension within temperature range $1,550-1,600{ }^{\circ} \mathrm{C}$

Regarding the surface tension, the measured data were normally distributed as proven by Shapiro-Wilk test. All linear models (see Table 2) were statistically significant at the significance level of $5 \%$ (F-test). According to Kruskal-Wallis test, the oxygen influenced the surface tension $(p<0.001)$, i.e., the differences in surface tension were statistically significant at all observed oxygen levels. This is also evidenced by the corresponding boxplot (Figure 2).

Table 2 Linear parameters of surface tension temperature dependence

\begin{tabular}{|c|c|c|c|c|c|c|}
\hline Sample & $\boldsymbol{T}_{\text {ref }}\left({ }^{\circ} \mathbf{C}\right)$ & $\boldsymbol{\sigma}_{\text {ref }}\left(\mathbf{m N} \cdot \mathbf{m}^{-1}\right)$ & $\boldsymbol{d} \boldsymbol{\sigma} / \mathbf{d} \boldsymbol{T}\left(\mathbf{m N} \cdot \mathbf{m}^{-1} \cdot{ }^{\circ} \mathbf{C}-\mathbf{1}\right)$ & $\boldsymbol{\Delta T}\left({ }^{\circ} \mathbf{C}\right)$ & $\boldsymbol{T}_{\mathbf{l}} \mathrm{DTA}\left({ }^{\circ} \mathbf{C}\right)$ & $\boldsymbol{T}_{\boldsymbol{I}} \mathbf{F S}\left({ }^{\circ} \mathbf{C}\right)$ \\
\hline $\mathbf{1}$ & 1,550 & $1,355.3$ & $543.3 \cdot 10^{-3}$ & $1,550-1,600$ & 1,527 & 1,528 \\
\hline $\mathbf{2}$ & 1,550 & $1,163.5$ & $1,717.9 \cdot 10^{-3}$ & $1,550-1,600$ & 1,527 & 1,529 \\
\hline $\mathbf{3}$ & 1,550 & $1,095.8$ & $1,852.3 \cdot 10^{-3}$ & $1,550-1,600$ & 1,528 & 1,529 \\
\hline
\end{tabular}

Using equation (1), the surface tension can be expressed as a function of temperature. Calculated parameters are listed in Table 2.

$\sigma(T)=\sigma_{\text {ref }}+\frac{d \sigma}{d T} \cdot\left(T-T_{\text {ref }}\right)$

where $\sigma_{\text {ref }}\left(\mathrm{mN} \cdot \mathrm{m}^{-1}\right)$ is surface tension at reference temperature $T_{\text {ref }}\left({ }^{\circ} \mathrm{C}\right)$, and $d \sigma / d T\left(\mathrm{mN} \cdot \mathrm{m}^{-1} \cdot{ }^{\circ} \mathrm{C}^{-1}\right)$ denotes temperature coefficient of surface tension.

The temperature dependences of the wetting angles are in Figure 3, pointing out that there was only a very slight dependence on the temperature, and, in the case of sample 2, almost none. Moreover, as the oxygen 
content of the steel increases, the wetting angles decreases. Figure 4 shows images of sample 2 assembly at certain temperatures, including wetting angles at $1,500{ }^{\circ} \mathrm{C}$ and $1,600^{\circ} \mathrm{C}$.

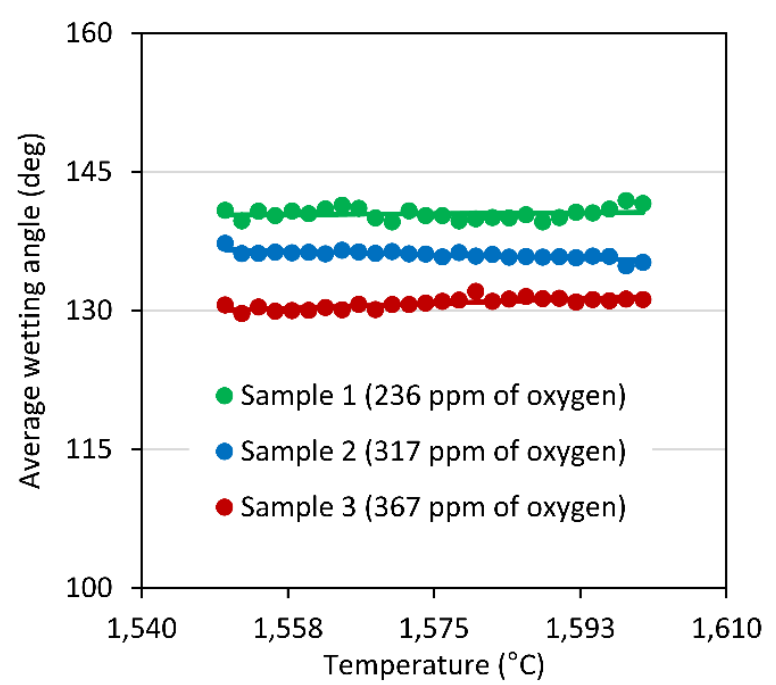

Figure 3 Average wetting angle depending on temperature
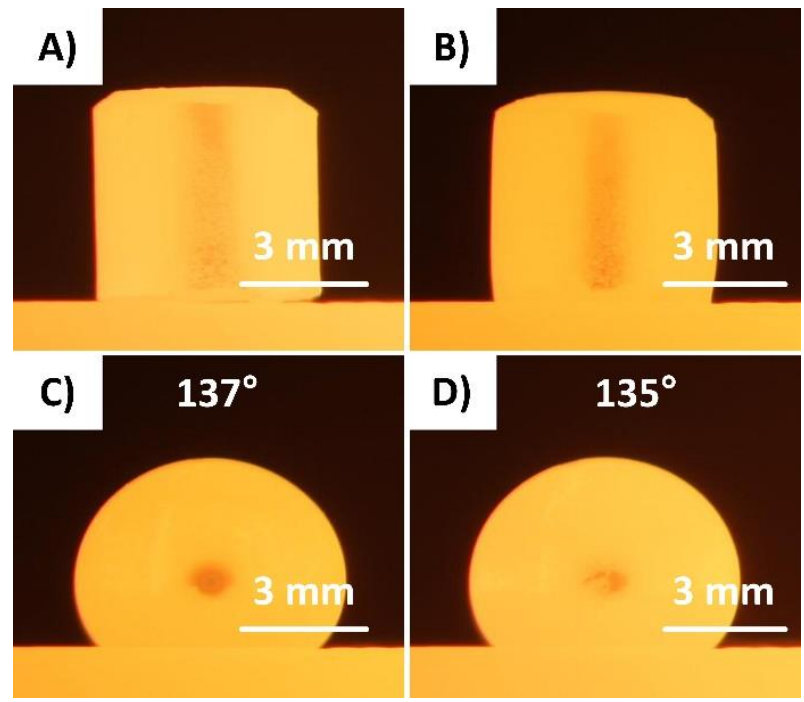

Figure 4 Images of sample 2 resting on alumina substrate at selected temperatures $\mathrm{A}) 1,500^{\circ} \mathrm{C}, \mathrm{B}$ )

$$
\left.1,530^{\circ} \mathrm{C}, \mathrm{C}\right) 1,550^{\circ} \mathrm{C}, \text { D) } 1,600{ }^{\circ} \mathrm{C}
$$

Steel liquidus temperatures were determined experimentally by the DTA method ( $T_{1}$ DTA) and subsequently compared with theoretically calculated using the FactSage software $(T, F S)$, with a high agreement (see Table 2).

\subsection{Mechanism of wetting}

After the wetting test, the diffraction patterns of the substrate corresponding to sample 2 showed a split in corundum diffraction lines referring to two corundum phases of different lattice parameters. The more intensive corundum phase is the normal corundum, while the second is Cr doped corundum causing a violent tint at the point of contact with steel [13]. No other phases were found (Figure 5).

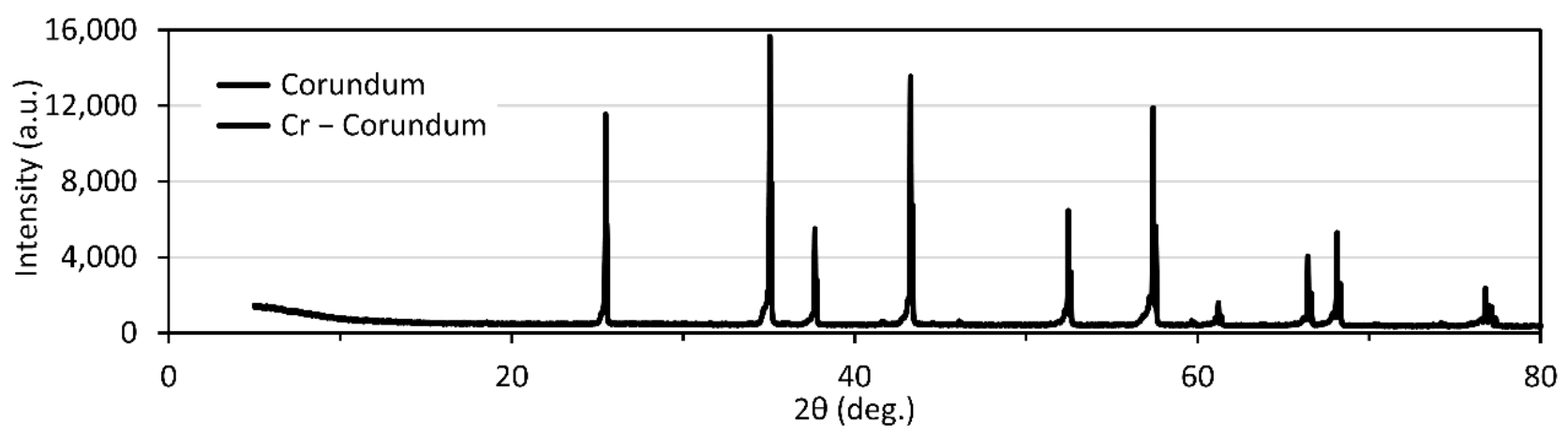

Figure $5 \mathrm{XRD}$ analysis of corundum substrate after wetting test of sample 2

To elucidate the wetting mechanism and deeply investigate the interactions occurring at the phase interface, we performed a FactSage simulation of the sample 2 arrangement (Figure 6). As regards the steel, the dominant phases were FCC and BCC steel matrices up to approximately $1,520{ }^{\circ} \mathrm{C}$ when they were swiftly suppressed by a liquid phase reaching a maximum at $1,529^{\circ} \mathrm{C}$. Besides, the formation of various oxides, carbides, and sulfides also occurred at a broad temperature range but to a much lesser extent. On the other 
hand, in the case of corundum substrate, the evolution of phases was more intriguing. The most abundant was corundum, which was altered in favor of calcium aluminosilicate, melilite, and hibonite, beginning at $<500{ }^{\circ} \mathrm{C}$, $735^{\circ} \mathrm{C}$, and $1,110^{\circ} \mathrm{C}$, respectively. Even though hibonite concentration was more prominent than $10 \mathrm{wt}$. \%, it was not detected by XRD and EDX analyses like the other two mentioned phases. Of particular interest is the partial melting of the substrate surface at temperatures above $1,425{ }^{\circ} \mathrm{C}$ which could affect the wetting. Additionally, garnet was present until the temperature of $735^{\circ} \mathrm{C}$.

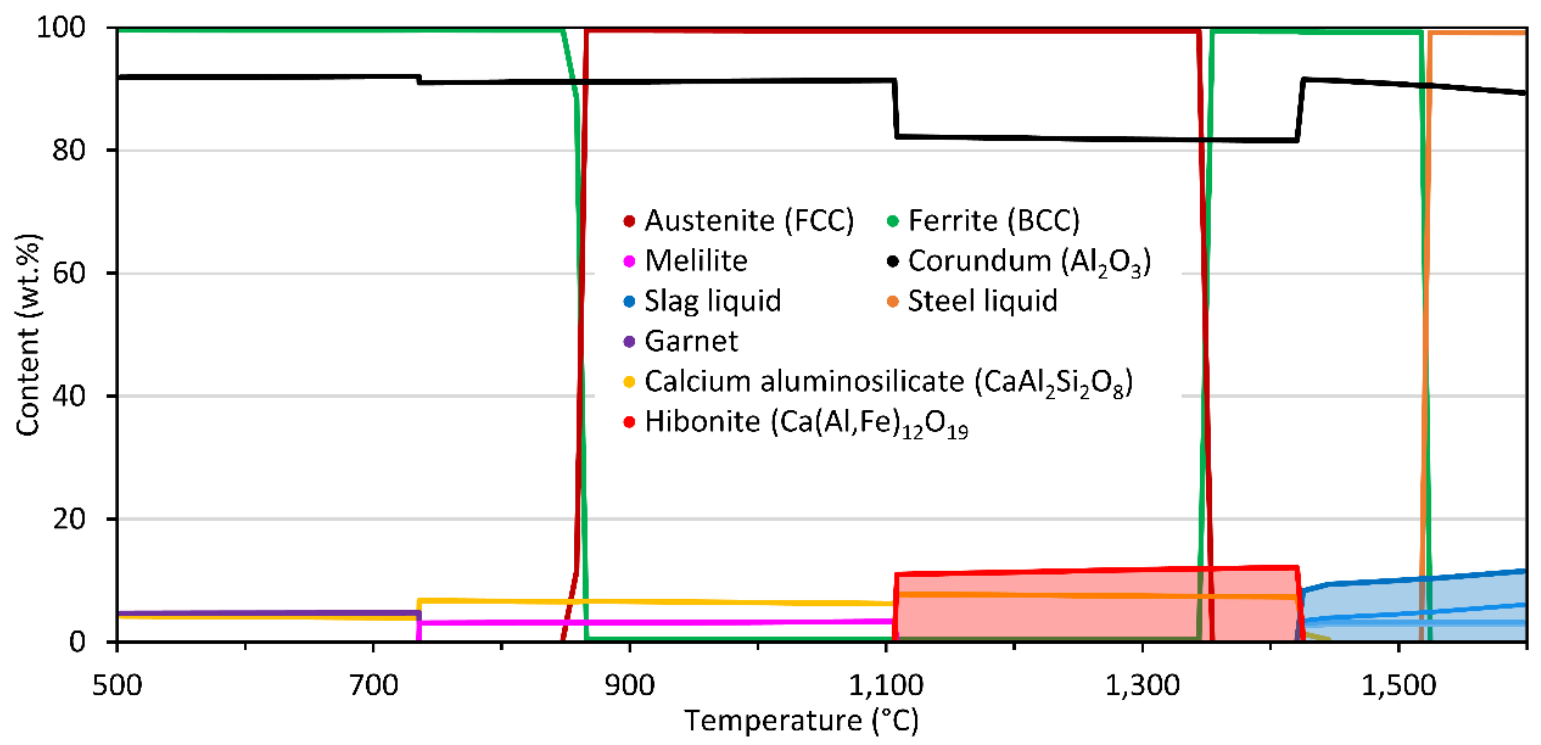

Figure 6 Interaction between alumina substrate and sample 2 calculated using FactSage 7.2

Moreover, the SEM analysis was carried out to characterize the microstructures of steel-corundum couple. Due to the higher oxygen content in the investigated steels, chromium, a relatively weak deoxidant, formed a fine ragged chromia layer on the droplet surface (Figure 7A) [14], which prevented the formation of a droplet in the early stages (Figure 4B). For this reason, the temperature dependences of the surface tension and the wetting angles are given only as from $1,550^{\circ} \mathrm{C}$. The area of corundum substrate around the drop remained unchanged except that $\mathrm{Fe}$, Cr-rich small-sized particles were observed there (Figure 7B). As for the area under the droplet, the corundum substrate was partially melted (Figure 7C), bearing identical steel particles.
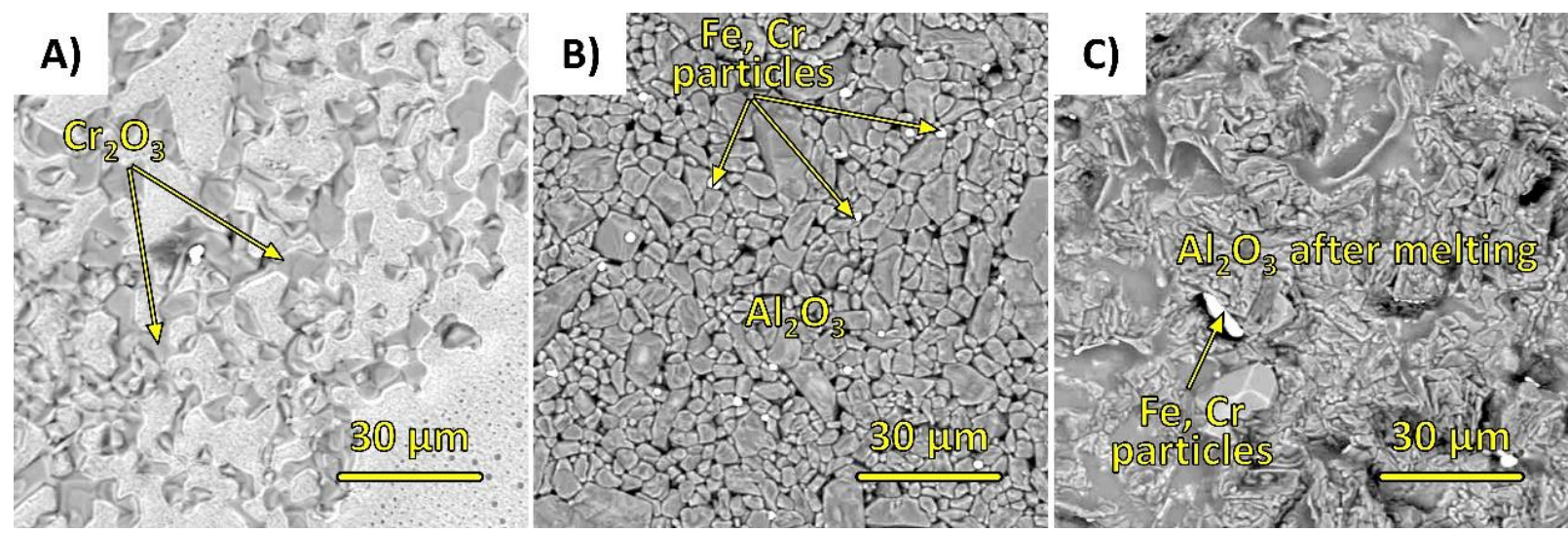

Figure 7 SEM images of sample 2 assembly. A) free droplet surface, B) unwetted area, C) wetted area

If we combine the results presented so far in this section, it can be assumed that non-reactive or inner wetting occurred during the experiments [15]. 


\section{CONCLUSION}

In this work, the wetting of alumina substrate by chromium steel with higher oxygen content was analyzed, and the results can be summarized as follows:

- The surface tension of the investigated steels increases slightly with temperature and decreases with increasing oxygen content of steels.

- The wetting angles were almost independent of the temperature within the given temperature range $\left(1,550^{\circ} \mathrm{C}\right.$ and $\left.1,600^{\circ} \mathrm{C}\right)$ and decreased with increasing oxygen content.

- $\quad$ The higher oxygen content (up to nearly $400 \mathrm{ppm}$ ) caused the formation of a thin chromia layer. This limited the determination of surface properties by the sessile drop method.

- The results of SEM and XRD analyzes confirmed non-reactive wetting. Only chromium-doped corundum was found on the corundum surface under the drop. The structure of the remaining surface area has not changed.

\section{ACKNOWLEDGEMENTS}

This paper was created within the frame of the project No.CZ.02.1.01/0.0/0.0/17_049/0008399 from the EU and CR financial funds provided by the Operational Programme Research, Development and Education, Call 02_17_049 Long-Term Intersectoral Cooperation for ITI, Managing Authority: Czech Republic - Ministry of Education, Youth and Sports, and student projects SP2021/68 and SP2021/41.

\section{REFERENCES}

[1] Classification of Carbon and Low-Alloy Steels. [online]. 2021. [viewed: 2021-03-22]. Available from: https://www.totalmateria.com/articles/Art62.htm.

[2] OAKEY, J.E. Power Plant Life Management and Performance Improvement. Sawston, Cambridge: Woodhead Publishing, 2011.

[3] SINGH, R. Applied Welding Engineering: Processes, Codes, and Standards. Kidlington, Oxford: ButterworthHeinemann, 2015.

[4] NESBITT, B. Handbook of Valves and Actuators: Valves Manual International. Jordan Hill, Oxford: ButterworthHeinemann, 2007.

[5] FERON, D. Nuclear Corrosion Science and Engineering. Philadelphia: Woodhead Publishing, 2012.

[6] McNALLAN, M.J., DEBROY, T. Effect of temperature and composition on surface tension in Fe-Ni-Cr alloys containing sulfur. Metallurgical Transactions B. 1991, vol. 22, no. 4, pp. 557-560.

[7] XIAO, F., LIU, L. X., YANG, R. H., ZHAO, H. K., FANG, L., ZHANG, C. Surface tension of molten Ni-(Cr, Co, W) alloys and segregation of elements. Transactions of Nonferrous Metals Society of China. 2008, vol. 18, no. 5, pp. 1184-1188.

[8] OZAWA, S., SUZUKI, S., HIBIYA, T., FUKUYAMA, H. Influence of partial pressure of oxygen on surface tension and its temperature coefficient of molten iron. Journal of Applied Physics. 2011, vol. 109, no.1, art. no. 014902.

[9] MOROHOSHI, K., UCHIKOSHI, M., ISSHIKI, M., FUKUYAMA, H. Surface Tension of Liquid Iron as Functions of Oxygen Activity and Temperature. ISIJ International. 2011, vol. 51, no. 10, pp. 1580-1586.

[10] EGRY, I., RICCI, E., NOVAKOVIC, R., OZAWA. S. Surface tension of liquid metals and alloys - Recent developments. Advances in Colloid and Interface Science. 2010, vol. 159, no. 2, pp. 198-212.

[11] OZAWA, S., MOROHOSHI, K., HIBIYA, T. Influence of Oxygen Partial Pressure on Surface Tension of Molten Type 304 and 316 Stainless Steels Measured by Oscillating Droplet Method Using Electromagnetic Levitation. ISIJ International. 2014, vol. 54, no. 9, pp. 2097-2103.

[12] ŘEHÁČKOVÁ, L., NOVÁK, V., VÁŇOVÁ, P., MATÝSEK, D., KONEČNÁ, K., SMETANA, B., DOBROVSKÁ, J. High-temperature interaction of molten Fe-C-O-Cr alloys with corundum. Journal of Alloys and Compounds. 2021, vol. 854 , art. 157128. 
[13] AHN, Y. K., SEO, J. G., PARK, J. Diffusion of chromium in sapphire: The effects of electron beam irradiation. Journal of Crystal Growth. 2011, vol. 326, no.1, pp. 45-49.

[14] MUKAI, K., LI, Z., ZEZE, M. Surface Tension and Wettability of Liquid Fe-16 mass\%Cr-O Alloy with Alumina. Materials Transactions. 2002, vol. 43, no. 7, pp. 1724-1731.

[15] KUMAR, G., PRABHU, K.N. Review of Non-reactive and Reactive Wetting of Liquids on Surfaces. Advances in Colloid and Interface Science. 2007, vol. 133, no. 2, pp. 61-89. 